\title{
Concepções de ser professor e motivos de escolha pela docência em Educação Física
}

\begin{abstract}
RESUMO: Objetiva-se identificar as concepções de ser professor de estudantes do curso de licenciatura em Educação Física, compreender a escolha pela profissão docente e as influências das experiências vividas no curso de graduação (primeira etapa), nas decisões relacionadas à carreira profissional na docência. A pesquisa, qualitativa, foi desenvolvida em uma Universidade pública do estado de São Paulo, com 20 graduandos, por intermédio de questionário aberto. Para os participantes, ser professor é ser um agente de transformação e um profissional detentor de conhecimento, mas que se relaciona com os alunos numa perspectiva horizontal. Os motivos de escolha pela docência perpassam pela identificação com a área da Educação Física e da docência, experiências acadêmicas e pessoais, bem como por questões socioprofissionais. A maioria dos participantes pretende seguir a carreira docente. Conclui-se que as concepções de ser professor e as escolhas profissionais resultaram, sobretudo, de representações construídas na trajetória de vida dos estudantes e das influências da primeira etapa do curso de graduação.
\end{abstract}

Palavras-chave: Licenciatura. Formação docente. Educação Física.

\section{Introdução}

A presente pesquisa insere-se na temática da formação de professores, enfatizando as concepções de ser professor de graduandos, a escolha pela profissão docente e as possíveis influências da formação inicial - nomeadamente a primeira etapa do curso, comum às modalidades de licenciatura e bacharelado - nas decisões relacionadas à carreira profissional no campo da docência em Educação Física.

As concepções a respeito do que significa ser professor, bem como a identidade docente, são construídas ao longo de toda a trajetória profissional e pessoal do estudante/professor, a saber: período escolar, formação inicial e percurso na carreira, conforme destaca Dubar (2005).

Folle e demais autores (2009, p. 31) ressaltam que a escolha pela profissão pode ser determinada por diversos aspectos da vida de uma pessoa, sejam sociais, pessoais, familiares e, até mesmo, educacionais. Contudo, Tartuce, Nunes e Almeida (2010) constatam que a maioria das motivações para a escolha e permanência na docência fundamenta-se em relações pessoais, tanto no aspecto afetivo e social quanto no aspecto econômico. Ao questionarem
Bárbara Turra

Universidade Estadual Paulista (UNESP)

barbaraturra@outlook.com Catia Silvana da Costa Instituto Federal de Educação, Ciência e Tecnologia do Mato Grosso do Sul (IFMS) catia.costa@ifms.edu.br Fernanda Rossi Universidade Estadual Paulista (UNESP)

fernandarossiunesp@gmail.com 
(1) O tronco comum tem duração de dois anos e meio (para o curso integral) e três anos (para o curso noturno). A integralização do curso é de quatro anos para o integral e cinco anos para o noturno. alunos do Ensino Médio sobre a possibilidade de ingressar na carreira docente, as autoras constataram que entre aqueles que optaram pelos cursos ligados às disciplinas integrantes da Educação Básica, a maioria escolheu a profissão Educação Física em decorrência da afinidade com a área.

Ao transpor a reflexão para o período de formação nos cursos de licenciatura, cabe ponderar sobre a construção e reconstrução de concepções pelos futuros professores. Soares e Bejarano (2008) defendem que os julgamentos, as explicações, as interpretações e as atitudes dos professores nas práticas pedagógicas são fundamentadas em suas crenças, não só profissionais, mas também naquelas constituídas no percurso de vida pessoal. Entretanto, os autores constatam que os cursos de formação docente não consideram as crenças dos professores e futuros professores em seus processos formativos, sendo urgente repensar os currículos, pois as crenças exercem forte influência sobre a seleção dos saberes e a prática pedagógica docente.

Diante desse contexto, o objetivo deste artigo consistiu em identificar as concepções de ser professor de estudantes do curso de licenciatura em Educação Física, compreender a escolha pela profissão docente e as influências das experiências vividas no curso de graduação (primeira etapa) nas decisões relacionadas à carreira profissional na docência.

O estudo foi realizado num curso de licenciatura em Educação Física de uma universidade pública estadual paulista. Determina o currículo do referido curso que os estudantes cursem uma etapa comum a todos os ingressantes, a qual consiste em períodos com disciplinas comuns à profissão Educação Física, no âmbito das dimensões do conhecimento do corpo humano, do ser humano e da sociedade e da dimensão da produção do conhecimento. Esse período é denominado de tronco comum. ${ }^{1}$

Transcorrida pouco mais da metade do processo de formação, os estudantes devem optar pela modalidade: bacharelado ou licenciatura. Essa escolha, inicialmente, ocorre conforme a opção do estudante, mas o projeto político-pedagógico do curso determina 40 vagas de ingresso, sendo 20 para cada modalidade. Diante disso, se o número de interessados por uma modalidade ultrapassar as 20 vagas - o que geralmente ocorre com o curso de bacharelado -, faz-se necessário utilizar um critério relacionado ao aproveitamento do curso para a classificação dos estudantes. Os excedentes, 
embora tenham optado pelo bacharelado, são redirecionados ao curso de licenciatura.

Esse fato traz à tona a problemática de direcionar estudantes para a licenciatura que não desejavam cursar esta modalidade, o que pode gerar a não identificação com a formação, desmotivação e evasão do curso. Os documentos legais da área educacional preconizam que a formação inicial tenha um projeto com identidade própria de curso, conforme a Resolução CNE/CP n. ${ }^{\circ}$ 2/2015 que define as Diretrizes Curriculares Nacionais para a formação inicial de professores. (BRASIL, 2015)

Para tanto, de acordo com a deliberação CEE n. ${ }^{\circ}$ 154/2017 do Conselho Estadual de Educação do Estado de São Paulo, desde o início do curso - incluindo todas as matérias ou atividades -, o estudante deve estar em conexão com a realidade da escola, mobilizando e articulando conhecimentos específicos - os objetos de ensino - aos conhecimentos pedagógicos. (SÃO PAULO, 2017)

Para a maioria dos participantes desta pesquisa não houve a necessidade de utilizar o critério de aproveitamento de seleção para cada modalidade. Contudo, no momento de escolha os graduandos ainda não haviam iniciado os estágios curriculares supervisionados na escola e contavam com algumas experiências no campo escolar. A falta de oportunidade para vivenciar e construir conhecimentos e experiências relacionados à docência na educação básica pode dificultar uma tomada de decisão mais consciente, de acordo com a especificidade da profissão, além de gerar impacto na tomada de decisão de seguir ou não nesta área de atuação e na (re)construção das concepções sobre o que significa ser professor.

Silva (2009, p. 12) afirma que "[...] no processo de formação para a docência é necessário ter como núcleo de esclarecimento, a compreensão da vida como um todo, isto é: pessoal e profissional". Corroborando a autora, esperamos que o estudo contribua para a ampliação do conhecimento no âmbito da formação inicial de professores, com ênfase nas influências que as experiências formativas da graduação propiciam ao graduando e em sua importância para a construção das concepções e escolhas profissionais.

\section{Metodologia}

A pesquisa fundamentou-se na abordagem qualitativa, a qual apresenta as seguintes características: o pesquisador deve estar 
diretamente envolvido com o ambiente no qual será realizada a pesquisa neste estudo, uma universidade pública paulista - e atentar-se - e procurar identificar a visão das pessoas que estão sendo pesquisadas nesse caso, os estudantes de um curso de licenciatura em Educação Física. (LUDKE; ANDRÉ, 2012)

A pesquisa foi desenvolvida no segundo semestre de 2015, com 20 graduandos do curso de licenciatura em Educação Física, sendo sete estudantes do período noturno - cinco do sexo masculino e dois do sexo feminino; e 13 estudantes do período integral - oito do sexo masculino e cinco do feminino. Para a coleta dos dados foi utilizado como instrumento o questionário, considerando as colocações de Gil e demais autores (2004, p. 80): "Os questionários devem ser estruturados com uma série de perguntas escritas, elaboradas previamente, com a finalidade de averiguar a opinião dos indivíduos aos quais se destinam, sobre algum tema específico".

Uma das vantagens da utilização do questionário como técnica de coleta na pesquisa qualitativa é a possibilidade de obtenção de dados de um número significativo de pessoas, permitindo, assim, que uma análise futura seja mais minuciosa e não necessite de uma adaptação para cada participante, como pode ocorrer com a técnica de entrevista. (GIL et al.,2004)

O questionário foi aplicado no início da primeira disciplina de estágio curricular supervisionado - coincidente com o início do curso de licenciatura - e foi norteado pelos seguintes temas: o significado de ser professor; motivos de escolha pelo curso de licenciatura em Educação Física; experiências nos primeiros anos da graduação que influenciaram na sua escolha pelo curso de licenciatura.

Os participantes assinaram um Termo de Consentimento Livre e Esclarecido (TCLE) e o estudo foi aprovado pelo Comitê de Ética em Pesquisa da Faculdade de Ciências da Unesp, Bauru. Para a identificação dos estudantes participantes adotamos as siglas E1, E2 e assim por diante.

A análise dos dados gerados foi embasada nos pressupostos da análise de conteúdo, que Bardin (2000, p. 38) define como "um conjunto de técnicas de análise das comunicações, que utiliza procedimentos sistemáticos e objetivos de descrição do conteúdo das mensagens", sendo pertinente para o estudo das motivações, atitudes, valores, crenças e tendências do grupo de graduandos pesquisado. 
As categorias de análise foram geradas a priori, com base no referencial teórico e objetivos do estudo, e no processo de análise as categorias foram desmembradas em subcategorias. Primeiramente foi feita a transcrição das respostas dos questionários para organização dos dados. Iniciamos a pré-análise com a leitura flutuante e a elaboração de indicadores, com base nas similaridades e descompassos encontrados nas respostas dos graduandos.

Na sequência, realizamos as operações de codificação, com a descrição analítica dos dados orientada pelos referenciais teóricos, e identificamos as unidades de registro e a classificação e agregação dos dados, desdobrando nas subcategorias de análise. A fase final consistiu no tratamento dos resultados obtidos e interpretação do corpus à luz da literatura.

Concluído o processo de categorização, a análise e discussão dos resultados com respaldo na literatura são apresentadas, na sequência, nas seguintes categorias e subcategorias:

Categoria 1) "O que é ser professor: concepções de estudantes de licenciatura em Educação Física". Esta categoria contempla as manifestações a respeito dos significados de ser professor nas subcategorias: "o professor como agente de transformação", "o professor como transmissor de conhecimentos" e "o professor que ensina e aprende".

$\mathrm{Na}$ categoria 2) "Os motivos de escolha pela licenciatura em Educação Física" discutem-se as expressões dos graduandos sobre as influências acadêmicas, socioprofissionais e pessoais em suas escolhas profissionais, nas subcategorias: "identificação com a área", "estabilidade na carreira", "experiências durante a graduação", "o professor como agente de transformação e transmissão do conhecimento" e "influências familiares e/ou escolares".

Por fim, a categoria 3) "Expectativas com a carreira docente em Educação Física" traz à discussão as pretensões positivas dos graduandos em relação a seguir a carreira docente, bem como relatos que indicam dúvidas em investir na docência depois de formados.

\section{Concepções e motivações para a escolha pela licenciatura em educação física}

Com base nos relatos dos graduandos do curso de licenciatura em Educação Física identificamos e discutimos, primeiramente, as concepções relacionadas ao que significa ser professor. Em seguida, 
enfatizamos os motivos que levaram esses graduandos a optarem pelo curso de licenciatura em Educação Física. Completando as análises, destacamos as expectativas dos graduandos para com a carreira docente, no intuito de elucidar suas motivações e dúvidas quanto ao prosseguimento na docência.

\subsection{O que é ser professor: concepções de estudantes de licenciatura em Educação Física}

No decorrer da vida, um estudante estabelece contato com diversos professores e, em virtude disso, constrói como fruto das experiências escolares, conceitos e características em relação a esses profissionais, podendo ser tanto positivas quanto negativas. Com o ingresso na graduação, uma nova relação professor-aluno é estabelecida, sendo que mediante os conhecimentos adquiridos e as novas experiências, as concepções vão sendo reconstruídas, algumas são reforçadas, outras desconstruídas e novas visões são constituídas, particularmente no que diz respeito ao que significa ser professor.

Ao analisar as respostas dos participantes nesta categoria foram estabelecidas três subcategorias de acordo com a incidência dos relatos, a saber: "o professor como agente de transformação", "o professor como transmissor de conhecimentos" e "o professor que ensina e aprende".

Refletir sobre "o professor como agente de transformação", subcategoria citada por 13 estudantes, significa analisar esse profissional do ponto de vista social, considerando o contexto em que está inserido. Sacristán (1999, p. 65) define que "o conceito de profissionalidade docente está em permanente elaboração, devendo ser analisado em função do momento histórico concreto e da realidade social que o conhecimento escolar pretende legitimar, em suma, tem de ser contextualizado".

Para Saviani (1997), o professor deve produzir e construir o conhecimento e, para que possa mediar o processo de ensino e aprendizagem no âmbito escolar, contribuindo para a formação do aluno, precisa ter domínio dos conhecimentos de sua área e do campo da educação. Além disso, o professor também deve saber compreender o movimento da sociedade, identificando suas características básicas e as tendências de sua transformação.

A concepção de ser professor ultrapassa a ideia do educador como um especialista em educação e no conteúdo que leciona, 
o professor assume - ou deveria assumir - um papel ainda mais relevante que este, articulando seus conteúdos com as condições sociais, econômicas e políticas que envolvem a instituição escolar. (CANDAU, 1981)

De acordo com um dos participantes da pesquisa, ser professor "é mostrar o caminho, por mais difícil que seja, alguém tem o dever de mostrar caminhos melhores [...]" (E4). Como podemos observar na resposta de E6, "ser professor é ser agente de transformação de uma realidade, observando obviamente que toda sua ação depende desde políticas voltadas para área até o seio familiar". E7 também expressa a ideia sobre esta função social quando diz que "ser professor exige muita responsabilidade, pois é a profissão que pode produzir novos conhecimentos a partir da relação com seus alunos e principalmente que forma o sujeito, contribuindo para transformações pautadas em valores e princípios". Já E16 manifesta que "ser professor é influenciar pessoas a serem melhores no decorrer do processo educacional. Basicamente, é proporcionar ao mundo pessoas melhores".

Podemos verificar em tais respostas que o professor tem função fundamental na construção social dos estudantes, pois exerce grande influência em suas vidas, fornecendo base e suporte para a formação de cidadãos e, também, pessoas éticas, contribuindo diretamente para o desenvolvimento da sociedade na qual esses alunos se inserem.

A segunda subcategoria, "o professor como transmissor de conhecimentos", engloba as manifestações de dez estudantes. Destacam-se os relatos: "professor para mim é aquela pessoa capacitada para transmitir o conhecimento adquirido ao longo do tempo para os alunos, de maneira crítica e reflexiva para que ocorra uma transformação na vida do aluno" (E1); "na minha visão, professor é exemplo, o detentor máximo de conhecimento, que sabe de tudo e se atualiza a todo o momento" (E5). Segundo E7, "é a profissão que ensina o conhecimento produzido pela humanidade". E12 completa: "transmitir o conhecimento não só aos seus alunos, mas a todos que o rodeiam".

Para Luckesi (2011, p. 145), o educador deve ter conhecimentos e habilidades suficientes para que ocorra uma elevação cultural no aluno e "[...] deve possuir algumas qualidades: compreensão da realidade com a qual trabalha, comprometimento político, competência no campo teórico de conhecimento em que atua e competência técnico-profissional". 
A subcategoria "o professor que ensina e aprende" contempla seis relatos. Os graduandos expressaram que o professor realiza uma troca mútua de conhecimento com seus alunos, sem associá-lo a um indivíduo que seria detentor exclusivo do saber. E8 cita que ser professor "é ensinar e aprender para e com o aluno. É ajudar e cooperar, despertar curiosidade". De acordo com o relato de E13, podemos refletir que ser professor "é fazer a ponte de conhecimento professor-aluno. Ensinar e aprender ao mesmo tempo".

Para E18, "ser professor é ensinar e aprender com os alunos, trocar conhecimentos, ajudar os alunos a evoluírem". E17 também expressa nitidamente este ponto de vista da relação professor-aluno quando diz: "é, ao mesmo tempo, conseguir ensinar os meus conhecimentos para os alunos e aprender o que eles podem me ensinar".

De acordo com a Tendência Progressista Libertadora discutida por Luckesi (2011), baseada nas concepções de Paulo Freire, o professor e os alunos têm papéis fundamentais na construção do ensino e da aprendizagem, ambos são responsáveis por essa construção e portadores de conhecimento. Formam, assim, uma relação horizontal. Portanto, embora o professor seja detentor de certos conhecimentos, o aluno também domina conhecimentos de outra natureza.

Concluímos que os graduandos consideram que ser professor significa agir para a transformação social, é o profissional que está apto e capacitado para mediar seu conhecimento adquirido/construído no decorrer da formação para os alunos de maneira crítica e reflexiva para que, assim, possa incidir uma transformação na vida do aluno, lembrando que ambos são detentores de conhecimento e podem ensinar e aprender conjuntamente.

\subsection{Os motivos de escolha pela licenciatura em Educação Física}

Os motivos que levam à escolha de um curso de licenciatura podem ser intrínsecos e altruístas, relacionados à afinidade ou ao desejo de se tornar professor, ou extrínsecos, provenientes do meio familiar ou, até mesmo, de influências relacionadas à vida escolar. Além disso, os motivos intrínsecos e extrínsecos não são excludentes, ambos colaboram no momento da tomada de decisão.

De acordo com Folle e Nascimento (2008, p. 610), os motivos para a escolha da profissão docente se relacionam à "[...] importância atribuída à motivação para a profissão, ou seja, a identificação de fatores de ordem pessoal, econômica e/ou social que influenciam 
a escolha da carreira docente". Esses motivos estarão relacionados diretamente à postura e ação que esse graduando assumirá no decorrer de sua carreira. Conforme destacam Silva e Krug (2012, p. 1031): "são inúmeras as lembranças que necessitam ser conhecidas para que se possa, realmente, compreender o universo de formação no qual os professores estão inseridos e o sentido que ser professor assume e assumirá no decorrer da carreira".

Para a discussão dos motivos que orientaram a escolha de ser professor dos participantes da pesquisa, elencamos cinco subcategorias de análise: "identificação com a área", "estabilidade na carreira", "experiências durante a graduação", "o professor como agente de transformação e transmissão do conhecimento" e "influências familiares e/ou escolares". Devemos considerar que, em alguns casos, os graduandos indicaram dois ou mais motivos para a escolha do curso de licenciatura em Educação Física.

$\mathrm{Na}$ primeira subcategoria, "identificação com a área", nove participantes expressaram sua afinidade com a área escolar e com a profissão como motivação para a definição pela licenciatura. Tais pontos de vista podem ser constatados nos seguintes relatos: "sempre admirei a profissão de professor, e Educação Física foi o que me atraiu, pois possibilita inúmeras possibilidades de atividades, trabalhos e aula, não ficando sempre na mesmice" (E5); "sempre quis trabalhar na área da educação e nunca gostei da forma como as outras disciplinas trabalham, desta forma escolhi Educação Física, entrei no curso e me descobri" (E18); "escolhi pela aparente afinidade com a área escolar" (E6); "porque é a área que mais me identifico" (E9).

E14, demonstra sua objeção em relação ao bacharelado e, consequentemente, sua maior afinidade para com a licenciatura: "não me identifiquei com a grade curricular do bacharelado e a vontade de fazer a diferença na vida dos estudantes como fazem na minha".

De acordo com Maschio e demais autores (2009), a identificação e o gosto pela profissão de professor devem ser concebidos de maneira positiva, pois descaracteriza, de certa maneira, o entendimento de que a escolha pela área da Educação Física está sempre relacionada ao gosto pelo esporte e pelas atividades físicas. Contudo, Folle e demais autores (2009, p. 32) identificaram em seu estudo que "Embora exista uma gama de fatores que podem influenciar na escolha pelo curso de Educação Física, parece que o esporte é um dos principais agentes de inserção e de motivação para a área". Razeira e demais autores (2014, p. 134) também destacam que o "[...] 
gosto pelo esporte é o motivo mais relevante para escolha do curso, e isso pode relacionar-se com a experiência anterior do sujeito".

Em relação ao grupo de estudantes desta pesquisa constatamos que a escolha pela profissão professor está relacionada diretamente à afinidade com a área, à admiração pela docência e à identificação com a profissão. O gosto pelo esporte não foi o elemento relatado, primordialmente.

$\mathrm{Na}$ subcategoria "estabilidade na carreira", três graduandos delinearam sua opção pelo curso em razão da condição estável que a carreira docente pode proporcionar, ideia que, na maioria das vezes, está diretamente relacionada ao êxito em concursos públicos. E3 destaca: "sempre tive a certeza de que queria fazer a licenciatura, tanto pela arte de ser professor quanto pela segurança que a licenciatura me dá com relação ao bacharelado". E4 também denota essa multiplicidade de motivos quando afirma que escolheu a licenciatura: "por experiências relacionadas ao curso e por acreditar que eu posso ser uma professora, como eu acredito que é. Também por saber que na área da Educação Física, dar aula em escola é mais seguro economicamente". Destacamos que a estabilidade na carreira foi apontada somente entre os graduandos do período noturno.

No estudo realizado por Galindo (2004) são indicados dois motivos relacionados à escolha pelo trabalho docente: à docência em primeiro lugar com $61 \%$, que seria o trabalho em si, o gosto de trabalhar com crianças e pela área de estudo e, em segundo, com $38 \%$, os benefícios materiais, relacionados à maior possibilidade de empregabilidade futura.

Com base em relatos de professores, Muhlstedt e Hagemayer (2015, p. 35) constataram que "há certa facilidade em conseguir o emprego de professor, afinal, os profissionais se aposentam, a população aumenta e as escolas necessitam de professores para existirem". Muitos estudantes ainda buscam segurança econômica e estabilidade, o que faz com que optem pela carreira de professor por esse motivo, pois, principalmente em relação ao bacharelado em Educação Física, a licenciatura é considerada, na visão dos estudantes, mais segura profissionalmente. A partir do momento em que o professor se insere em uma escola, seja por meio de um concurso público ou outro processo seletivo, os estudantes consideram que, financeiramente, estarão mais seguros.

A terceira subcategoria, "experiências durante a graduação", inclui os relatos de quatro graduandos em virtude das expressões 
relacionadas às influências diversificadas no decorrer do curso no tronco comum, primeira etapa da formação acadêmica, quando são mediados os conhecimentos considerados de base para o exercício da profissão Educação Física, independentemente da especialidade ou campo de atuação. Um dos estudantes, o E9, justifica sua escolha da seguinte maneira: "os motivos que me levaram a essa escolha foi pelo fato de estar inserida em projetos de extensão no âmbito escolar desde o primeiro ano". Podemos ver, também, na fala do E11, de forma sucinta, seu motivo pela escolha: "por causa de um projeto que participei no primeiro semestre".

É possível verificar a influência significativa que essas experiências geram na vida dos graduandos durante o curso, podendo direcionar suas escolhas profissionais.

Silva e Krug (2012, p. 1031) enfatizam que "Quando optamos por uma profissão, o que nos motiva a essa escolha são as identificações e os saberes que temos baseados nas nossas experiências e vivências e que fazem parte da nossa trajetória de vida". Os autores destacam a participação em grupos de estudos, projetos de pesquisa, ensino e extensão e estágios supervisionados como experiências formativas de relevante significado. Corroborando os autores, Costa (2017) identificou, nas histórias de vida de professores de Educação Física aposentados, saberes docentes cuja procedência se assenta em suas trajetórias extraescolares, escolares, formativas e profissionais.

Evidencia-se que as experiências no decorrer da graduação, como a participação em projetos de extensão, são de extrema importância para a escolha da carreira, principalmente em um curso com divisão entre licenciatura e bacharelado, pois com base nessas experiências, os graduandos têm um contato antecipado com o ambiente de trabalho, o que para muitos ocorre somente com o início dos estágios curriculares supervisionados. Igualmente importante é o investimento em projetos de pesquisa.

Soares e Bejarano (2008, p. 69) afirmam que os currículos de formação devem incluir "[...] a pesquisa como princípio formativo, para que os professores em formação, ao investigar a realidade escolar, possam rever a sua forma de pensar e agir no campo profissional, construindo uma postura investigativa".

Nesse sentido, os estudantes destacam como relevante durante a formação: "estar inserida em projetos de extensão da área escolar" (E4); "experiências de trabalhar com crianças com projetos sociais
(3) Programa Institucional de Bolsa de Iniciação à Docência - Ministério da Educação (MEC). 
envolvendo a capoeira à experiência do PIBID"3 (E3); "projeto de extensão em voleibol" (E11); "algumas disciptinas e projetos de extensões" (E18).

Silva e Krug (2012) apontam que os trabalhos executados em projetos da graduação geram experiências muito significativas na construção da carreira docente, possibilitando a formação de profissionais de qualidade.

Destacamos, também, as experiências de docência na escola, relacionadas às vivências que aconteceram no âmbito escolar, durante a graduação, e que contribuíram para a escolha dos graduandos pela licenciatura em Educação Física, como destacaram alguns dos participantes: "durante os primeiros semestres fizemos algumas atividades de observação em escola e o saldo foi bastante positivo" (E5); "dar aula de dança na escola e ver o quanto isso foi importante para as crianças, fazer estágio na escola e observar as crianças de perto" (E8).

Experiências relacionadas a projetos com foco na docência são relevantes no decorrer da graduação, pois por meio dessas experiências os graduandos têm contato com a realidade das escolas antes do desenvolvimento dos estágios curriculares supervisionados - que, no caso do lócus desta pesquisa, iniciam-se a partir da segunda metade do curso -, o que pode ser decisivo no momento da opção entre a licenciatura e o bacharelado, conforme os relatos permitem constatar.

Ainda em relação às experiências durante a graduação, destacaram-se aquelas relacionadas aos professores universitários, como podemos ver na fala do E6: "alguns professores influenciaram pela forma como davam suas aulas e pela compreensão na área (professores da graduação)". Reforçando essa ideia, E9 mostra como as ações e reflexões do professor da graduação podem ser determinantes na escolha do estudante: "os professores de licenciatura conseguiram despertar o meu interesse na área e por causa dos projetos voltados para a licenciatura".

Silva e Krug (2012, p. 1037) salientam o papel do professor formador e como suas ações afetam as escolhas dos graduandos:

[...] o professor formador tem um papel fundamental no processo formativo, pois está nele o compromisso de trazer para a sala de aula da universidade os fatos e exemplos concretos de que tem conhecimento para que todos os acadêmicos possam identificar o seu campo de trabalho. Além disso, é importante que o professor formador incentive seu aluno a buscar subsídios além dos oferecidos na sua formação. O processo de busca propicia ao aluno entender que se escolhemos ser professor 
é por que seremos eternos aprendizes nos mais diferentes contextos.

As experiências geradas nas disciplinas durante a graduação, o que inclui as metodologias e as dinâmicas utilizadas pelos professores, também podem exercer influência na decisão do graduando, conforme reflete E7:

As principais experiências da graduação que contribuíram para minha escolha estão relacionadas à metodologia utilizada nas disciplinas de caráter mais prático envolvendo esportes, dança, por exemplo, que promovem a aprendizagem por meio da ludicidade e da integração entre os participantes.

Com base nesses princípios, podemos observar E15, ao citar que "a experiência mais marcante é/foi sentar em roda, dar oportunidade de falar, não sentando enfileirado".

As rodas de conversa, por exemplo, quando bem orientadas, promovem a participação ativa do estudante nas discussões, sendo uma estratégia não convencional de formação que pode despertar a atenção e a conscientização, de quem participa, para outros fatores educativos.

Por fim, quatro participantes constataram que não tiveram nenhuma experiência na graduação que os influenciassem em suas escolhas.

A graduação é um leque de oportunidades para a construção de experiências e conhecimentos que podem influenciar as escolhas dos graduandos, seja por meio de projetos de extensão, de pesquisa, das ações educativas dos professores, das vivências nas disciplinas, bem como pela aproximação com o ambiente escolar. Nessas ações configuram-se momentos ricos de contato com a escola, nos quais o graduando se depara com o contexto de trabalho, gerando experiências e reflexões que podem influenciar na escolha pelo curso de licenciatura.

Na subcategoria "o professor como agente de transformação e transmissão do conhecimento", seis graduandos ressaltam a função do professor como principal influenciador de suas decisões profissionais. E7 corrobora essa perspectiva quando aponta seus motivos para a escolha da licenciatura:

escolhi o curso de licenciatura em Educação Física por ter a vontade de contribuir na formação das pessoas, de modo que sejam 
autônomas e esclarecidas sobre o conhecimento, para que tenhamo direito de escolh a efetivo, levando sempre em consideração valores e princípios que promovam a harmonia em sociedade.

Já E17 afirma: "pois me agrada a ideia de fazer parte de algo que possa ajudar alguém e acredito que ser professor pode ser uma boa maneira para isso acontecer".

Nesse sentido, Luckesi (2011, p. 146) chama a atenção para o processo de construção dos conhecimentos mediado pelos professores:

[...] ensinar não significa, simplesmente, ir para uma sala de aula onde se faz presente uma turma de alunos e 'despejar' sobre ela uma quantidade de conteúdos. Ensinar é uma forma técnica de possibilitar aos alunos a apropriação da cultura elaborada da melhor e mais eficaz forma possível.

Observamos, nesta subcategoria, que os graduandos expressam seus motivos de escolha fundamentados nas contribuições que poderão oferecer às pessoas com o exercício de sua profissão, desde o ato de ensinar conteúdos específicos ao outro até envolver-se com ações voltadas para a cidadania e a construção de uma sociedade mais justa.

A subcategoria "influências familiares e/ou escolares", última dessa categoria de análise e gerada com base nas respostas de três graduandos, remete ao fato de que pessoas do convívio desses estudantes podem influenciar direta ou indiretamente a vida e as escolhas dos mesmos.

Um caso de influência familiar é do E12, o qual relatou: "minha mãe é professora e isso me influenciou diretamente". Acrescentando o contexto escolar a essa motivação, E1 destaca: "os motivos que me levaram a essa escolha foram: meus pais, minha tia, meus professores do colégio, entre outros". Seguindo a linha de influência escolar, temos o relato de E15 que especifica, ainda, a afinidade pela área da Educação Física: "escolhi por gostar da Educação Física e me inspirar em um professor do Ensino fundamental".

Folle e Nascimento (2009) apontam que, em determinados casos, as escolhas se baseiam na influência de terceiros, e estas devem ser consideradas nas pesquisas, pois muitas vezes podem ser determinantes para a escolha da profissão, como no caso dos participantes apontados acima. Valério (2012) afirma que as influências familiares e escolares são muito fortes em relação à 
escolha do curso de graduação e no momento da decisão de qual carreira seguir. O autor verificou que $21 \%$ dos alunos apontaram a escolha pela licenciatura por influência familiar e 20\% indicaram influências escolares.

Constatamos que os motivos que orientam a escolha pela carreira docente do grupo de graduandos formam um mosaico, envolvendo identificação com a área da docência e da Educação Física, a busca pela estabilidade profissional, as influências ao longo das experiências vividas na graduação, bem como as influências familiares e de escolarização, além das concepções construídas sobre a função do professor como agente de transformação social.

\subsection{Expectativas com a carreira docente em Educação Física}

As variadas experiências formativas ao longo da graduação trazem consigo conflitos e incertezas. Nesse processo emergem, também, reflexões a respeito de decisões profissionais e pessoais, como, por exemplo, seguir ou não com a carreira escolhida (no caso deste estudo, a carreira docente).

Souto e Paiva (2013) abordaram em seu estudo, com graduandos do curso de Matemática, que cerca de 50\% dos estudantes que optaram pelo curso, pretendem seguir a carreira docente, porém, o índice de desistência é muito alto durante a formação.

Em relação a esta temática, estabelecemos duas subcategorias de análise: respostas afirmativas e respostas nas quais os graduandos ainda não se decidiram no que se refere à pretensão de seguir a carreira docente. Vale ressaltar que, durante a pesquisa, os estudantes se encontravam na segunda metade do curso, iniciando os estágios curriculares supervisionados, momento que tende a promover reflexões mais profundas sobre as escolhas profissionais e pessoais pelo contato constante com a cultura escolar e as práticas pedagógicas.

A maioria dos participantes (13 graduandos) respondeu positivamente em relação à escolha de seguir a carreira docente. O motivo de E5 fundamentou-se na ideia de que: "professor é algo impressionante". Enquanto E7 enfatizou a pretensão de ser professora, sem afirmar o interesse exclusivo pela atuação na educação básica escolar: "Pretendo ser professora, mas como quero ter o bacharelado também, pois é uma vertente da Educação Física que me agrada, posso ser professora em outros contextos, no sentido de que o profissional de Educação Física ensina e forma em qualquer lugar no qual possa atuar, 
não necessariamente na escola". Outro estudante ainda enfatizou: "pretendo, para que no futuro eu tenha uma experiência na área escolar e na mão na massa" (E4).

Dez participantes afirmaram que não têm certeza se seguirão na carreira docente ao término da graduação. Podemos observar essas respostas na fala do E1: "sobre esse assunto, ainda não tenho pensado, pois tenho outros objetivos em mente, como seguir carreira acadêmica, mas se tiver a oportunidade de lecionar em escolas, com certeza aceitaria". No caso do E6, existe a dúvida, pendendo mais para o aspecto negativo, uma vez que respondeu: "provável que não".

Constatamos que a maioria dos graduandos pretende seguir a carreira de professor quando terminar a graduação, mas ainda existem alguns estudantes com dúvidas quanto a essa decisão, apesar da escolha pelo curso de licenciatura no percurso da graduação.

De acordo com Tartuce, Nunes e Almeida (2010, p. 447), o "[...] processo de decisão profissional deve ser visto como resultado de fatores de natureza extrínseca e intrínseca, que se combinam e interagem de diferentes formas, gerando dilemas e tensões para quem o vivencia".

Podemos afirmar que as dúvidas sobre seguir ou não na carreira docente - que denotam certa incoerência por se tratar de relatos coletados no contexto da licenciatura - são representativas dos dilemas e tensões mencionadas pelas autoras supracitadas, que ainda relatam que:

\begin{abstract}
A perspectiva subjetiva inclui o modo pelo qual os indivíduos percebem as carreiras e a si próprios no contexto do trabalho, aí interferindo aspectos como identificação, autoconceito, interesses, habilidades, maturidade, valores, traços de personalidade e expectativas com relação ao futuro. Ao mesmo tempo, deve-se levar em conta que os contextos sociais em transformação interferem nas relações entre o indivíduo e o social e, dessa maneira, nas identidades sociais e profissionais.
\end{abstract} (TARTUCE; NUNES; ALMEIDA, 2010, p. 448)

Assim, entendemos que as expectativas com relação à carreira docente em Educação Física também podem se fundamentar em uma perspectiva que é subjetiva, conforme elucidam os nossos dados, uma vez que coletamos, concomitantemente, respostas afirmativas e respostas indecisas no que se refere à pretensão futura de atuar como professor. 


\section{Considerações}

Esta pesquisa, inserida no âmbito da formação inicial de professores, objetivou identificar as concepções de ser professor de estudantes do curso de licenciatura em Educação Física, compreender a escolha pela profissão docente e as influências das experiências vividas no curso de graduação (primeira etapa) nas decisões relacionadas à carreira profissional na docência.

A análise dos resultados permitiu constatarmos que os significados de ser professor para os estudantes entrevistados se assentam na ideia de uma atuação docente voltada para a transformação social e da vida dos alunos, buscando a formação de cidadãos e contribuindo diretamente com o desenvolvimento pessoal e com a sociedade. A atuação docente volta-se para a mediação crítica e reflexiva do conhecimento construído na formação inicial, na qual professor e alunos sejam detentores de conhecimento e possam ensinar e aprender mutuamente.

Em relação aos motivos que levaram à escolha do curso de licenciatura em Educação Física, destacaram-se a afinidade com a área, a admiração e a identificação com a profissão. Alguns graduandos justificaram essa escolha pelo fato de buscarem estabilidade e segurança econômica, o que poderia não ser encontrado com tanta facilidade em relação ao curso de bacharelado. Para alguns graduandos, há a influência das experiências decorrentes da graduação em suas escolhas, como aquelas relacionadas a projetos de extensão, principalmente pelo fato de estabelecer contato com a realidade das escolas, além de outras experiências advindas do contexto escolar.

A relação dos graduandos com os professores da graduação e os procedimentos didático-metodológicos adotados nas aulas também foram citados pelos graduandos como influências positivas na escolha pelo curso de licenciatura.

Outro motivo mencionado pelos graduandos foi a vontade de se constituir como um agente social de transformação e transmissão do conhecimento e, com isso, promover contribuições para as pessoas do entorno por meio do exercício da profissão. Alguns graduandos também citaram as influências relacionadas à família e à vida escolar como decisivas no momento da escolha pela carreira docente. 
Em relação a seguir ou não na carreira de professor quando concluir a graduação, a maioria dos estudantes pretende seguir, mas ainda existem alguns com dúvidas quanto a essa decisão, mesmo com a recente escolha pela modalidade da licenciatura. Os graduandos optaram pelo curso de licenciatura em Educação Física pela identificação com a área, pela estabilidade na carreira, pelas experiências na graduação, para serem agentes de transformação e transmissores do conhecimento e, ainda, pelas influências familiares e da vida escolar.

Destacamos a relevância deste estudo para o campo da formação inicial de professores, evidenciando elementos que contribuem para o entendimento da opção pela docência e as influências de diversas trajetórias nessa escolha. Nota-se que no início da formação, as experiências formativas no campo da licenciatura, para a maioria dos estudantes, foram incipientes, contudo, tiveram que optar por qual carreira seguir, tendo, por vezes, buscar em suas vivências particulares motivos para essa escolha. Evidencia-se, também, a importância do significado do que é ser professor para esses estudantes e seu papel na sociedade. Em relação aos estudantes que não haviam decidido por seguir ou não a carreira docente, há que se considerar que alguns não tiveram contato com o contexto escolar, o qual viria a ocorrer com os estágios curriculares supervisionados - momento relevante da graduação. É no ambiente de estágio que o graduando terá a oportunidade de reconhecer-se com a profissão escolhida, vivenciando o dia a dia à luz das reflexões teóricas e, por conseguinte, desenvolver mais experiências podendo, então, decidir com mais clareza pelo seguimento da carreira docente ou não.

As concepções do que é ser professor significam o entendimento a respeito da função deste profissional e são resultantes das representações construídas durante a trajetória de vida. Essas representações podem (ou não) ser reforçadas, (des)construídas e (re)construídas nos cursos de formação inicial, inclusive no tronco comum, momento do curso de Educação Física no qual o estudante ainda não tem como prioridade os conhecimentos específicos do campo da educação, sobretudo escolar.

As trajetórias da vida do estudante podem influenciar e contribuir para a configuração de suas escolhas profissionais. Todavia, considerando que o professor e as experiências ao longo da graduação exercem influência na construção social dos estudantes, constatamos que a formação no tronco comum pode contribuir 
para uma posterior escolha pelo curso de licenciatura e/ou por seguir ou não a carreira docente, ainda que o estudante opte pela licenciatura.

Embora as diretrizes curriculares nacionais para a formação de professores (BRASIL, 2015) reforcem a necessidade de identificação com a profissão docente desde o início do curso, a Resolução CNE/ CES n. ${ }^{\circ}$ 6, que institui as diretrizes dos Cursos de Graduação em Educação Física, publicada recentemente (BRASIL, 2018), determina que a formação na área tenha ingresso único, devendo o curso ser desenvolvido em duas etapas.

Assim, estabelece o artigo $5 .^{\circ}$ que a primeira etapa, denominada etapa comum, deve compreender o núcleo de estudos da formação geral, identificador da área de Educação Física; e a segunda, chamada etapa específica, refere-se à formação em conhecimentos específicos das opções do bacharelado ou da licenciatura. A justificativa arrolada no documento (art. 5. ${ }^{\circ}$ ) versa sobre "[...] a necessária articulação entre conhecimentos, habilidades, sensibilidade e atitudes requerida do egresso para o futuro exercício profissional". (BRASIL, 2018)

Concluímos que cursos de Educação Física organizados com etapas comuns às modalidades da licenciatura e do bacharelado podem dificultar a criação e consolidação de um perfil identitário para cada modalidade de atuação. Nesse ínterim, é relevante (re) pensar o curso de licenciatura como uma trajetória que contribua para o estudante seguir na carreira docente, reflexão que pode direcionar a novas pesquisas, uma vez que a concepção de ser professor e as tomadas de decisões profissionais - que também devem ser pensadas com base no momento histórico no qual os dados são coletados - influenciam na escolhas do estudante.

\footnotetext{
ABSTRACT: The objective of this study is to identify the conceptions of being a teacher of undergraduate students in Physical Education, to understand the choice of the teaching profession and the influences of the experiences undergraduate (first stage) in the decisions related to the professional career in teaching. The qualitative research was developed at a public university in the State of São Paulo, with twenty undergraduates, through an open questionnaire. For the participants, to be a teacher is to be a transformation agent and a professional holder of knowledge, but one that relates to the students in a horizontal perspective. The reasons for the choice of teaching are through identification with the area of Physical Education and teaching, academic and personal experiences, as well as socio-professional issues. Most of the participants intend to follow a teaching career. It is concluded that the conceptions of being a teacher and the professional choices resulted, above
} 
all, from representations built on the students' life trajectory and from the influences of the first stage of the undergraduate course.

Keywords: Graduation. Teacher training. Physical Education.

RESUMEN: Se pretende identificar las concepciones de ser profesor de estudiantes del curso de licenciatura en Educación Física, comprender la elección por la profesión docente y las influencias de las experiencias vividas en el curso de graduación (primera etapa) en las decisiones relacionadas a la carrera profesional en la docencia. La investigación, cualitativa, fue desarrollada en una Universidad pública del Estado de São Paulo, con veinte graduandos, por intermedio de cuestionario abierto. Para los participantes, ser profesor es ser un agente de transformación y un profesional poseedor de conocimiento, pero que se relaciona con los alumnos desde una perspectiva horizontal. Los motivos de elección por la docencia pasan por la identificación con el área de la Educación Física y de la docencia, experiencias académicas y personales, así como por cuestiones socioprofesionales. La mayoría de los participantes pretende seguir la carrera docente. Se concluye que las concepciones de ser profesore las eleccion es profesionales resultaron, sobre todo, de representaciones construidas en la trayectoria de vida de los estudiantes y de las influencias de la primera etapa del curso de graduación.

Palabras clave: Licenciatura. Formación docente. Educación Física.

\section{Referências}

BARDIN, Laurence. Análise de conteúdo. Lisboa: Edições 70, 2000.

BRASIL. Ministério da Educação. Resolução CNE/CP n ${ }^{0} 2$, de $1^{\circ}$. de julho de 2015. Define as Diretrizes Curriculares Nacionais para a formação inicial em nível superior (cursos de licenciatura, cursos de formação pedagógica para graduados e cursos de segunda licenciatura) e para a formação continuada. Diário Oficial da União, seção 1, Brasília, DF, p. 8-12, 2 jul. 2015.

BRASIL. Resolução CNE/CES nº 6, de 18 de dezembro de 2018.

Institui Diretrizes Curriculares Nacionais dos Cursos de Graduação em Educação Física e dá outras providências. Diário Oficial da União, seção 1, Brasília, DF, n. 243, p. 48-49, 19 dez.2018. .

CANDAU, Vera Maria. A formação de educadores: uma perspectiva multidimensional. A formação do educador: desafios e perspectivas. Rio de Janeiro: PUC, 1981. (Série Estudos).

COSTA, Catia Silvana da. Histórias de vida e saberes de professores de Educação Física que atuaram nos anos iniciais do ensino fundamental nas décadas de 1980 e 1990. 2017. Tese (Doutorado em Educação) Universidade Federal de São Carlos, São Carlos, 2017.

DUBAR, Claude. A socialização: construção das identidades sociais e profissionais. Tradução Andréa Stahel M. da Silva. São Paulo: Martins Fontes, 2005.

FOLLE, Alexandra; FARIAS, Gelcemar Oliveira; BOSCATTO, Juliani Daniel; NASCIMENTO, Juarez Vieira do. Construção da carreira 
docente em Educação Física: escolhas, trajetórias e perspectivas. Movimento, Porto Alegre, v. 15, n. 1, p. 25-49, jan./mar. 2009.

FOLLE, Alexandra; NASCIMENTO, Juarez Vieirado. Aderência à profissão Educação Física: estudo de casos no magistério público estadual de Santa Catarina. Revista da Educação Física/UEM, Maringá, v. 20, n. 3, p. 353-367, jul./set. 2009.

FOLLE, Alexandra; NASCIMENTO, Juarez Vieira do. Estudos sobre o desenvolvimento profissional: da escolha à ruptura da carreira docente. Revista da Educação Física/ UEM, Maringá, v. 19, n. 4, p. 605-618, 4.trim. 2008.

GALINDO, Wedna Cristina Marinho. A construção da Identidade profissional docente. Psicologia ciência e profissão, Brasília, DF, v. 24, n. 2, p. 14-23, 2004.

GIL, Juana Maria Sancho; HERNÁNDEZ, Fernando; NEGRINE, Airton; MOLINA, Rosane Maria Kreusburg. A pesquisa qualitativa na Educação Física. Porto Alegre: Sulina, 2004.

LUCKESI, Carlos Cipriano. Filosofia da educação. 3. ed. São Paulo: Cortez, 2011.

LUDKE, Menga; ANDRÉ, Marli Eliza Dalmazo Afonso. Pesquisa em Educação: abordagens qualitativas. São Paulo: EPU, 2012.

MASCHIO, Valéria; SILVA, Alexandra Rosa; BASEI, Andréia Paula; ILHA, Franciele Roos da Silva; KRUG, Hugo Norberto. As motivações para a escolha do curso de licenciatura em educação física: um diálogo com acadêmicos em formação inicial. Boletim Brasileiro de Educação Física, Brasília, DF, n. 73, p. 1-9, fev./mar.2009.

MUHLSTEDT, Alexandro.; HAGEMAYER, Regina Cely de Campos. Escolha da profissão e trajetórias de vida do professor. Caderno da Pedagogia, São Carlos, v. 8, n. 16, p. 28-39, jan./jun. 2015.

RAZEIRA, Maurício Berndt; TAVARES, Francisco José Pereira; PEREIRA, Flávio Medeiros; RIBEIRO, José Antonio Bicca; MACHADO, Carla Rosane Carret. Os motivos que levam à escolha do curso de licenciatura em Educação Física e as pretensas áreas de atuação. Revista Mackenzie de Educação Física e Esporte, São Paulo, v. 13, n. 2, p. 124-136, jul./dez. 2014.

SACRISTÁN, Gimeno. Consciência e ação sobre a prática como libertação profissional dos professores. In: NÓVOA, António (org.). Profissão professor. 2. ed., Porto: Porto Editora1, 1999. p. 63-92.

SÃO PAULO. Conselho Estadual de Educação de São Paulo. Deliberação CEE n. ${ }^{0}$ 154/2017. Dispõe sobre alteração da Deliberação CEE 111/2012. Diário Oficial, seção 1, São Paulo, v. 127, n. 106, p. 38-39, 7 jun. 2017.

SAVIANI, Dermeval. A função docente e a produção do conhecimento. Educação e Filosofia, Uberlândia, v. 11, n. 21/22, p. 127-140, jan./jun.jul./dez. 1997. 
SILVA, Alexandra Rosa; KRUG, Hugo Norberto. As trajetórias formativas de acadêmicos de Educação Física do curso de licenciatura da UFSM: contribuições na constituição do ser professor. Atos de Pesquisa em Educação, Blumenau, v. 7, n. 4, p. 1026-1052, dez. 2012.

SILVA. Marilda da. Complexidade da formação de professores: saberes teóricos e saberes práticos. São Paulo: Cultura Acadêmica, 2009.

SOARES, Ilma Fernandes; BEJARANO, Nelson Rui. Crenças dos professores e formação docente. Revista da Faced, Salvador, n. 14, p. 55-71, jul./dez. 2008.

SOUTO, Romélia Mara Alves; PAIVA, Paulo Henrique Apipe Avelar de. A pouca atratividade da carreira docente: um estudo sobre o exercício da profissão entre egressos de uma licenciatura em matemática. ProPosições Campinas, v. 24, n.1, 201-224. 2013.

TARTUCE, Gisela Lobo B. P.; NUNES, Marina M. R.; ALMEIDA, Patrícia Cristina Albieri De. Alunos do Ensino Médio e atratividade da carreira docente no Brasil. Cadernos de Pesquisa, São Paulo, v. 40, n. 140, p. 445-477, maio/ago. 2010.

VALÉRIO, Camila. Atratividade da carreira docente no curso de licenciatura em pedagogia: dilemas, escolhas e inserção profissional. 2012. Trabalho de Conclusão de Curso (Licenciatura em Pedagogia) - Instituto de Biociências, Universidade Estadual Paulista "Júlio de Mesquita Filho", Rio Claro, 2012.

Submetido em: $17 / 02 / 2019$

Aceito em:17/08/2019 